\title{
Propuesta Metodológica para el MONITOREO DE HUELLAS VEHICULARES EN COMUNIDADES VEGETALES PROTEGIDAS DEL DESIERTO
}

\author{
MeTHOdOLOGICAL PROPOSAL FOR MONITORING OF VEHICULAR TRACES ON \\ PROTECTED PLANT COMMUNITIES OF DESERT
}

\author{
Martín Guillermo Almirón*(D)
}

\begin{abstract}
CIGEOBIO (CONICET-UNSJ) Instituto de Geología Dr. Emiliano P. Aparicio. Cátedra de Botánica sistemática; Departamento de Biología (FCEFyN); Universidad Nacional de San Juan, Argentina.
\end{abstract}

*martinalmiron@conicet.gov.ar

Citar este artículo

ALMIRÓN, M. G. 2020. Propuesta metodológica para el monitoreo de huellas vehiculares en comunidades vegetales protegidas del desierto. Bol. Soc. Argent. Bot. 55: 243-251.

DOI: https://doi. org/10.31055/1851.2372.v55. n2.25480

Recibido: 22 Septiembre 2019 Aceptado: 27 Abril 2020

Publicado: 30 Junio 2020

Editor: Ramiro Aguilar (D)

ISSN versión impresa 0373-580X ISSN versión on-line 1851-2372

\section{SUMMARY}

Background and aims: The transit of vehicles within protected areas constitutes a threat to the natural heritage that must be evaluated. The high operational cost of monitoring these activities makes it necessary to develop quick and simple evaluation alternatives that allow having a first parameter of trends. Using freeware and basic techniques, I propose a study case to evaluate the increase in vehicle traces for the period 2004-2018 and their potential impact on the vegetation of the Loma de Las Tapias protected area, San Juan, Argentina.

M\&M: Using pre-existing floristic zoning and two sets of satellite images (2004-2018), vehicle traces were quantified with a grid, and these squares were categorized according to: absence of traces; old traces (2004); new traces (2018) and relapsing traces (2004-2018) on the different floristic units.

Results: Currently, from the 223 squares that constitute the grid, only $35 \%$ showed no vehicular traces, while $13.9 \%$ had only old ones, $30 \%$ relapsing traces and the remaining $21.1 \%$ had new vehicular traces. The increase during the evaluated period was uniform in all floristic units.

Conclusions: The proposed methodology was simple and fast and allowed detecting the increase of vehicular traces in the area, establishing reference values for subsequent evaluations. The observed increase of traces emphasizes the need to focus on conservation efforts and to incorporate new thematic layers to enrich the management of the protected area.

\section{KEY WORDS}

Protected areas, desert, vehicular traces, environmental impact, vegetation.

\section{REsumen}

Introducción y objetivos: El tránsito de vehículos sobre el terreno de áreas protegidas, constituye una amenaza al patrimonio natural que debe ser evaluada. El alto costo operativo de monitorear estas actividades hace que sea necesario desarrollar alternativas de evaluación rápidas y simples que permitan tener un primer parámetro de tendencias. Mediante freeware y técnicas básicas, se propone como caso de estudio evaluar las huellas vehiculares durante el período 2004-2018 y su potencial impacto en la vegetación del área protegida Loma de Las Tapias, San Juan, Argentina.

M\&M: Empleando la zonificación florística preexistente y dos sets de imágenes satelitales (2004-2018), se cuantificaron las huellas vehiculares con una grilla, cuyos cuadros fueron categorizados según: ausencia de huellas; huellas antiguas (2004); huellas nuevas (2018) y huellas reincidentes (2004-2018) sobre las diferentes comunidades vegetales.

Resultados: Actualmente, de los 223 cuadros que constituyen la grilla, solo el $35 \%$ no posee huellas vehiculares, mientras que el $13,9 \%$ posee únicamente huellas antiguas, el $30 \%$ huellas reincidentes y el $21,1 \%$ restante posee huellas vehiculares nuevas. Por lo tanto, se observa un claro incremento de huellas durante el período evaluado, que fue uniforme en todas las unidades florísticas.

Conclusiones: La metodología propuesta resultó sencilla y rápida y permitió detectar el incremento de huellas en el área, estableciendo así valores de referencia para posteriores evaluaciones. El incremento de huellas observado, enfatiza la necesidad de priorizar la conservación y de incorporar nuevas capas temáticas para enriquecer la gestión del área protegida.

Palabras clave

Áreas protegidas, desierto, huellas vehiculares, impacto ambiental, vegetación. 


\section{INTRODUCCIÓN}

El monumento natural y paisaje protegido Loma de las Tapias (5000 ha) fue creado en el año 2002 por la Ley Provincial $\mathrm{N}^{\circ} 7307$ para preservar el paisaje típico de huayquerías y el yacimiento fosilífero de vertebrados del Mioceno tardíoPlioceno temprano, con una antigüedad estimada en $\sim 7.8 \mathrm{Ma}$ (Contreras \& Baraldo, 2011), que otorgan al área relevancia científica, educativa y turística. Su cercanía a la ciudad Capital de San Juan y al dique de Ullum, donde se emplazan complejos recreativos, contribuye a que numerosos visitantes (mayoritariamente locales) concurran en días feriados y fines de semana para desarrollar actividades al aire libre, tanto dentro del área como en su periferia. Dichas actividades comprenden principalmente recorridos en bicicletas todo terreno, cuatriciclos y motocross, que, sumadas a caminatas diurnas y nocturnas, representan un importante uso por parte de la comunidad.

Muchas de estas actividades están reguladas por la Secretaría de Estado de Ambiente y Desarrollo Sustentable de la provincia y se desarrollan sobre circuitos preexistentes e incluyen competencias deportivas. Sin embargo, una gran cantidad de usuarios ingresan y transitan en el área con vehículos todo terreno (en adelante OHV, por sus siglas en inglés off-highway vehicle) sin autorización, abriendo nuevas huellas. Esto es en parte facilitado porque el área posee muchas entradas desde sus márgenes (cauces de ríos temporarios, abanicos aluviales, entre otras) y está atravesada de suroeste a noreste por la ruta provincial $\mathrm{N}^{\circ} 79$, a partir de la cual ingresan con sus vehículos al área protegida, generando nuevas huellas donde no había. Si bien no hay estadísticas oficiales, la realidad en Loma de Las Tapias se asemeja a la de otras áreas del mundo donde en las últimas décadas ha proliferado de modo alarmante el uso de OHV (Goossens et al., 2012; Navas Romero et al., 2019), priorizándose así la evaluación de estas actividades para que los órganos de gestión y control puedan alcanzar los objetivos de conservación.

Esta problemática comenzó a expandirse principalmente en ambientes áridos y semiáridos (Brooks \& Lair, 2005; Kelly, 2014; Psaralexi et al., 2017; Navas Romero, et al., 2019), donde la vegetación escasa no representa una barrera infranqueable para la circulación de vehículos (Brooks \& Lair, 2005). En diversos sitios se han constatado efectos negativos en el ambiente tanto en sus componentes abióticos como la dinámica hidrológica y la estabilidad del suelo (Duniway et al., 2010), como así también en indicadores bióticos como la estructura, riqueza y cobertura vegetal (Kelly, 2014; Grenke et al., 2018; Navas Romero et al., 2019). Esta alteración ambiental se agrava en sitios con pendiente pronunciada y comunidades vegetales poco resilientes (Cole \& Bayfield, 1993) y en sitios con suelos de textura fina (Bratton et al., 1979). La evaluación tradicional de este tipo de impactos posee en general un alto costo operativo en logística y tiempo (Duniway et al., 2010), por lo que el desarrollo de métodos más eficientes y expeditivos permitirá un manejo más efectivo (Grenke et al., 2018) y la toma de decisiones a corto plazo.

El objetivo del presente trabajo es comparar el trazado de huellas por la circulación de OHV en el Parque Natural protegido Lomas de las Tapias durante el período 2004 - 2018, y su posible efecto en las comunidades vegetales del parque, detalladas en un trabajo previo (Almirón, 2018). Debido al aumento en las actividades turísticas en torno al área protegida (Contreras, 2010), se predice un incremento de las huellas detectables en el período evaluado desde 2004 a 2018. Por otro lado, debido a que las diferentes unidades florísticas se ubican en sectores del área protegida igualmente accesibles a cualquier $\mathrm{OHV}$, se plantea la hipótesis de que el incremento de huellas durante el período estudiado es uniforme en las diferentes unidades florísticas.

\section{Materiales y Métodos}

\section{Área de estudio}

El área de estudio se sitúa en la provincia geológica de la Precordillera de San Juan, Argentina ( $31^{\circ} 28^{\prime}$ S $-68^{\circ} 40^{\prime} \mathrm{W}$; Fig. 1A). Está constituida por una secuencia sedimentaria plegada controlada tectónicamente por las megafracturas de las Salinas Grandes y Villicum-Zonda y por procesos de erosión hídrica superficial y sub-superficial favorecidos por disolución pseudokárstica (Suvires \& Contreras, 2011). El relieve está comprendido 


\section{G. Almirón - Evaluación de huellas vehiculares en áreas protegidas}

por la exposición en superficie de sedimentos agrupados en tres formaciones correspondientes al Mioceno tardío-Plioceno temprano (Contreras \& Baraldo, 2011): la formación "Loma de Las Tapias" con un miembro inferior (Limolitas La Colmena) y uno superior (Areniscas Albardón) y las formaciones "Mogna" y "El Corral", determinadas por conglomerados fluviales y aluviales respectivamente, que corresponden a los sitios de mayor altitud del área (Loma de Ullum y Loma de Las Tapias), (Rodríguez, 2004). Estas formaciones están expuestas a partir de un plegamiento anticlinal que corre en sentido NE-SW, intensamente erosionado. Al este del anticlinal se encuentra el plegamiento sinclinal "Las Tapias", cubierto por sedimentos cuaternarios del Holoceno (Suvires \& Contreras, 2011).

De acuerdo al modelo fitoclimático de Köppen (1931), el clima del área es del subtipo BWwkb, desértico híper árido. La precipitación media anual es de $84 \mathrm{~mm}$, ocurriendo el $72 \%$ durante el período estival. La temperatura media anual es de $20^{\circ} \mathrm{C}$, con una media máxima de $40{ }^{\circ} \mathrm{C}$ y una media mínima de $16{ }^{\circ} \mathrm{C}$ (Poblete \& Minetti, 1999) provocando un importante déficit hídrico la mayor parte del año.

Desde el punto de vista florístico, el área está inserta en la Provincia Fitogeográfica del Monte (Cabrera, 1976), correspondiendo fisonómicamente a un matorral de arbustos xerófilos esparcidos y de escasa cobertura. Las familias botánicas con mayor número de especies son: Compositae y Poaceae (9 c/u), Fabaceae (8), Cactaceae y Solanaceae (6 c/u) y Zigophyllaceae (4) (Almirón, 2018). En ese mismo trabajo se destacan cuatro comunidades florísticas determinadas por el tipo de sustrato, la pendiente del terreno y la altitud (Fig.1B). La unidad 1 corresponde a un matorral de Deuterocohnia longipetala Mez y Larrea cuneifolia Cav., ubicado en laderas elevadas $(915,6 \mathrm{msnm})$ de alta pendiente que coinciden con los conglomerados Mogna y El Corral, cuya cobertura vegetal promedio alcanza el 51,9 \%. La unidad 2 está definida por un matorral de L. cuneifolia y Zuccagnia punctata Cav. con una cobertura vegetal de 46,2 $\%$, ubicado altitudinalmente bajo la unidad anterior (830 msnm). La unidad 3 está determinada por un arbustal de Larrea divaricata ubicado en faldeos suaves sobre depósitos cuaternarios disectados por cauces temporarios, con una cobertura vegetal promedio de $41,7 \%$. Finalmente, la unidad 4 representa la comunidad de menor cobertura vegetal promedio (15\%), emplazada sobre las arcillas y limos salinos de los miembros La Colmena y Albardón, siendo Atriplex spegazzinii A. Soriano ex Múlgura y Z. punctata los arbustos dominantes. En esta comunidad, la vegetación está dispuesta mayoritariamente sobre los cauces temporarios y sitios donde se acumula la escasa agua precipitada.

En el área de estudio se han relevado 17 especies endémicas en diferentes categorías y prioridades de conservación (Plantas endémicas de la Argentina, http://www.lista-planear-org/), destacándose Pyrrhocactus sanjuanensis (Speg.) Backeb., A. spegazzinii, Aphyllocladus ephedroides Cabrera y Gomphrena cladotrichoides Suess entre otras, que aumentan el valor del área como sitio de resguardo de la vegetación endémica argentina (Godoy-Bürki et al., 2014; Almirón, 2018).

\section{Metodología}

Con el fin de simplificar y hacer accesible la propuesta metodológica de este trabajo, se buscaron alternativas para desarrollar capas temáticas con software de acceso libre y uso sencillo. Mediante el empleo de Q-Gis ${ }^{\circledR}$ (Q-Gis, 2019; versión 3.4), se creó una capa vectorial con los límites del área y posteriormente se creó una grilla mediante el siguiente comando:

Pestaña "vectorial" $\rightarrow$ "herramientas de investigación" $\rightarrow$ “crear cuadrícula".

Se configuró el tipo de cuadrícula (línea), determinando un espaciado horizontal y vertical de 500 metros, sin superposición. El tamaño de los cuadros de la grilla $(500$ x $500 \mathrm{~m})$ se eligió como un buen balance entre la calidad de visualización de huellas en el terreno y el esfuerzo en el procedimiento. Posteriormente, dicha cuadrícula fue recortada de acuerdo a los límites del área con el siguiente comando:

Pestaña "vectorial" $\rightarrow$ "herramientas de geoproceso" $\rightarrow$ "cortar".

De esta manera se obtuvo la nueva y definitiva capa vectorial con la grilla ajustada a los límites legales del área protegida, consistente en 223 cuadros (algunos completos y otros incompletos, dada la irregularidad del perímetro).

Todas las capas vectoriales fueron proyectadas en el sistema WGS 84 en coordenadas geográficas y exportadas al formato. $\mathrm{kml}$ (Keyhole Markup Language) para ser posteriormente 

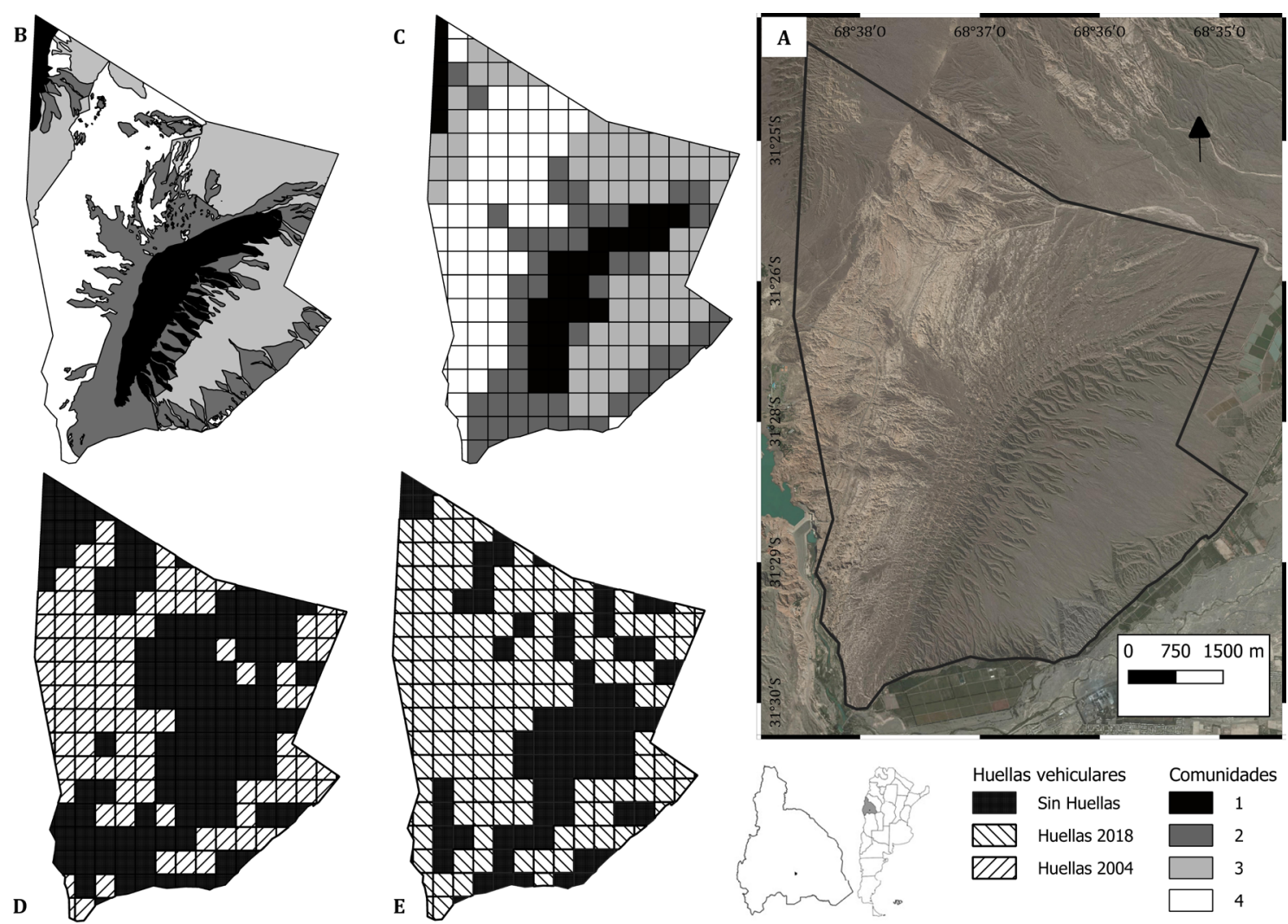

Fig. 1. Monumento Natural y Paisaje Protegido "Loma de Las Tapias", San Juan (Argentina). A: imagen general del área de estudio. B: Mapa florístico tomado de Almirón (2018). C: Categorización de cuadros de acuerdo a la comunidad vegetal de mayor cobertura porcentual en cada cuadro. D-E: Distribución de cuadros con y sin huellas vehiculares según la imagen del año 2004 y 2018, respectivamente.

utilizadas en el freeware Google Earth Pro®. En dicho software, mediante el comando "imágenes históricas", se accedió a dos sets de imágenes satelitales en dos períodos definidos: uno próximo a la creación del área (2004) y uno actualizado (2018), con el fin de detectar variaciones temporales en la aparición de huellas observables. De este modo, también queda abierta la posibilidad de futuras comparaciones con otros sets de imágenes satelitales posteriores. A fin de validar la herramienta satelital, se seleccionaron al azar 20 celdas que fueron posteriormente recorridas corroborando en el terreno la presencia/ausencia de huellas correspondientes observadas en las imágenes satelitales.

Cada cuadro de la grilla fue observado en los dos sets de imágenes (2004 y 2018), categorizándose según cuatro alternativas posibles:
- sin huellas detectables en ninguna imagen (SH)

- con huellas detectables en la imagen 2004 (huellas antiguas) (HA)

- con huellas detectables en la imagen 2018 (huellas nuevas) (HN)

- con huellas antiguas (2004) y nuevas (2018) (huellas reincidentes) (HR)

Cabe destacar que la fauna del área estudiada consta de zorros y micromamíferos, por lo que las huellas detectadas en las imágenes satelitales tienen inequívocamente origen antrópico. Esto además fue corroborado por observación directa en el terreno.

Por otro lado, el mapa de vegetación de Loma de Las Tapias (Fig.1B, tomado de Almirón, 2018) fue superpuesto a la misma grilla empleada anteriormente, con el fin de categorizar cada 


\section{G. Almirón - Evaluación de huellas vehiculares en áreas protegidas}

cuadro a partir de la comunidad vegetal con mayor porcentaje dentro de sus límites (Fig.1C). Posteriormente se superpusieron las capas creadas con el fin de contabilizar los cuadros con y sin huellas en ambos períodos (Fig.1D-E), respecto a cada cuadro según comunidad vegetal.

Para determinar si hubo un incremento en la cantidad de huellas entre 2004 y 2018, para el total de los cuadros se calculó el porcentaje de cambio en el número de huellas como: ((\#huellas 2018 - \#huellas 2004) / \#huellas 2004) x 100. De esta forma, valores negativos del porcentaje de cambios implican una reducción de huellas de 2004 a 2018 y valores positivos indican un incremento en las huellas. Por otro lado, mediante el test de $\mathrm{Chi}^{2}(\alpha \leq 0,05 ; 3$ g. 1.), se comparó la frecuencia observada de cuadros $\mathrm{HN}$ en cada unidad florística con su frecuencia esperada, según la hipótesis de que el incremento fue uniforme. Para ello, se obtuvo la frecuencia total de cuadros $\mathrm{HN}$ en toda el área a partir del total de cuadros HN (47) dividido en el total de cuadros del área (223). El número de cuadros $\mathrm{HN}$ esperados en cada unidad se obtuvo según el número de cuadros por unidad florística x la frecuencia total de cuadros HN. Ya que los cuadros reincidentes también determinan el incremento de huellas en el área, se comprobó también si el incremento de la suma de cuadros HN y HR en cada unidad florística fue uniforme. Para ello, la frecuencia de cuadros $\mathrm{HN}+\mathrm{HR}$ en toda el área se obtuvo de acuerdo a la suma de todos los cuadros HN (47) más los cuadros HR (67), dividida en el total de cuadros del área (223). Esta frecuencia fue multiplicada por el número de cuadros de cada unidad florística con el fin de obtener el número de cuadros $\mathrm{HN}+\mathrm{HR}$ esperado en cada caso.

\section{Resultados}

En el set de imágenes 2004 se observó una prevalencia de cuadros sin huellas $(56,1 \%)$ respecto a los que sí poseyeron huellas $(43,9 \%)$, mientras que en el 2018 cambió la proporción de cuadros con huellas $(65,0 \%)$ en relación a los sin huella (35,0 \%) (Fig. 1D-E; Tabla 1).El porcentaje neto de cambio a través de todas las celdas fue de un incremento de huellas del $48 \%$ desde 2004 a 2018 (Tabla 1) lo cual confirma el patrón esperado inicialmente. De los 223 cuadros totales del área, actualmente el 13,9\% corresponde a HA, el 30,0\% HR y el 21,1\% restante a HN (Tabla 2). A valores actuales, todas las unidades florísticas presentaron huellas antiguas y nuevas, que ordenadas en forma decreciente a partir del porcentaje de cuadros afectados por huellas son: 4 (76,5\%); $3(65,8$ $\%) ; 2(60,0 \%)$ y $1(44,4 \%)$. La Tabla 2 sintetiza las proporciones de cuadros en las diferentes categorías, de acuerdo a cada comunidad vegetal en el período actual (2018).

La frecuencia total de cuadros $\mathrm{HN}$ fue de 0,2108 , por lo que los valores esperados dependieron del número de cuadros contabilizados en cada comunidad: $(1=5,69 ; 2=11,59 ; 3=15,39$ y $4=$ 14,33). Estos valores fueron comparados con los cuadros HN observados en cada unidad (Tabla 2). Si bien en la unidad 2 se observó el mayor incremento de cuadros $\mathrm{HN}$, no se encontraron diferencias significativas en dicha categoría $\left(\chi^{2}=\right.$ $0,906 \mathrm{p}=0,824)$.

$\mathrm{La}$ frecuencia de cuadros $\mathrm{HN}+\mathrm{HR}$ en toda el área fue 0,5112 que multiplicada por el número de cuadros en cada comunidad determinan los cuadros esperados según la hipótesis de incremento uniforme

Tabla 1. Conteo de cuadros con y sin huellas en los dos sets de imágenes satelitales (2004-2018), en las cuatro comunidades vegetales observadas en el área de estudio.

\begin{tabular}{|cccccc|}
\hline $\begin{array}{c}\text { Comunidades } \\
\text { Vegetales }\end{array}$ & Sin huella & 2004 & Con huella & Sin huella & Con huella \\
1 & 21 & 6 & 15 & 12 \\
2 & 36 & 19 & 22 & 33 \\
3 & 40 & 33 & 25 & 48 \\
4 & 28 & 40 & 16 & 52 \\
Totales & $\mathbf{1 2 5}$ & $\mathbf{9 8}$ & $\mathbf{7 8}$ & $\mathbf{1 4 5}$ \\
\hline
\end{tabular}




\section{Tabla 2. Síntesis de categorias de cuadros en la actualidad (2018), sobre las diferentes comunidades vegetales del área protegida Loma de Las Tapias. Sin huellas (SH); huellas antiguas (HA); huellas reincidentes (HR) y huellas nuevas (HN).}

\begin{tabular}{|cccccc|}
\hline Comunidades vegetales & $\mathbf{( S H )}$ & $\mathbf{( H A )}$ & $\mathbf{( H R )}$ & $\mathbf{( H N )}$ & $\begin{array}{c}\text { Totales/ } \\
\text { comunidades }\end{array}$ \\
\hline 1 & 15 & 2 & 4 & 6 & 27 \\
2 & 22 & 6 & 13 & 14 & 55 \\
3 & 25 & 8 & 25 & 15 & 73 \\
4 & 16 & 15 & 25 & 12 & 68 \\
Totales/ categorías & $\mathbf{7 8}$ & $\mathbf{3 1}$ & $\mathbf{6 7}$ & $\mathbf{4 7}$ & $\mathbf{2 2 3}$ \\
\hline
\end{tabular}

de huellas $(1=13,8 ; 2=28,1 ; 3=37,3$ y $4=34,8)$. En este caso, el aumento de cuadros afectados por la sumatoria $\mathrm{HN}+\mathrm{HR}$ también resultó uniforme en todas las unidades florísticas $\left(\chi^{2}=1,429 \mathrm{p}=0,699\right)$.

Considerando la extensión de las comunidades a partir de la cantidad de cuadros que ocupan en el área, se observó que la comunidad 1 es la que posee mayor proporción de superficie sin huellas observables, coincidiendo con los sitios de mayor altitud y pendiente, escabrosidad y dureza del terreno, donde afloran los conglomerados (Almirón, 2018). En las otras tres comunidades se observaron las mayores proporciones de cuadros con huellas de algún tipo, prevaleciendo en la comunidad 2 la presencia de cuadros $\mathrm{HN}$ y $\mathrm{HR}$, mientras que en la comunidad 3 de menor pendiente y suavidad del relieve prevaleció HR y posteriormente HN. En la comunidad 4, con menor cobertura vegetal y donde el sedimento es más fino y la pendiente del terreno es menor, desciende drásticamente la proporción de cuadros SH y aumenta la proporción de cuadros en categoría HR, seguidos de HA.

\section{Discusión y Conclusiones}

A pesar de contar con un marco jurídico adecuado, la realidad actual en Loma de Las Tapias dista de ser la ideal. El alarmante incremento de huellas vehiculares observado a partir de los cambios en la proporción de cuadros con y sin huellas durante el período estudiado, pone de manifiesto la necesidad de priorizar la conservación del patrimonio natural, determinando sitios y actividades específicas reguladas.
A partir del empleo de la metodología propuesta en el presente trabajo, resultó posible detectar un importante aumento en el trazado de huellas de vehículos desde la creación del área a la actualidad, estableciendo así valores de referencia de uso en dos períodos concretos (2004 y 2018), posibilitando futuros monitoreos en función de la adquisición de imágenes satelitales actualizadas. La selección del tamaño de los cuadros resulta clave, ya que cuadros más pequeños implican mayor precisión y mayor esfuerzo de trabajo (y viceversa). En áreas extensas en las que el número de cuadros resulte elevado, es posible realizar mediante la grilla muestreos aleatorios, regulares ó estratificados, dependiendo de las hipótesis y objetivos planteados. En el caso particular del ANP Loma de Las Tapias, el bajo número de cuadros permitió categorizarlos a todos en los dos sets de imágenes satelitales en aproximadamente cuatro horas de trabajo, por lo que la cuantificación temporal y espacial de huellas vehiculares fue sencilla y rápida.

La principal limitación encontrada, implica la imposibilidad de discriminar en las imágenes satelitales cómo los diferentes vehículos produjeron las huellas y cuál fue la frecuencia de tránsito (Grenke et al., 2018). Esto es solucionable realizando ensayos complementarios en el terreno con otras metodologías, en función de cada pregunta (Hosier \& Eaton, 1980; Navas Romero, et al. 2019). Otra limitante podría surgir en ambientes de mayor humedad donde la vegetación, al recuperarse más rápidamente, podría dificultar la detección de huellas en las imágenes satelitales. Metodológicamente, la mayoría de los trabajos existentes comparan determinadas propiedades del 


\section{G. Almirón - Evaluación de huellas vehiculares en áreas protegidas}

suelo y de la vegetación sobre las huellas y sobre sitios ubicados en sus inmediaciones, considerados como control experimental (Kutiel et al., 2000; Navas Romero et al., 2019), o sobre gradientes desde las huellas hacia zonas periféricas menos afectadas (Brooks and Lairs, 2005; Grenke et al., 2018). Estas metodologías son consistentes a micro escala o en ambientes homogéneos, pero pierden su capacidad de predecir en ambientes heterogéneos donde intervienen nuevas variables. Por otro lado, los entes controladores de las áreas protegidas suelen requerir información en el corto plazo para la toma de decisiones de manejo, que sean extrapolables a la totalidad del área. Por ello, considerar celdas de mediana escala como unidades de evaluación, permitiría incluir variables de relevancia a través de mapas temáticos sencillos de toda el área, potenciando la herramienta de manejo y analizando tendencias a partir de imágenes satelitales de diferentes períodos.

A partir del marco hipotético del presente trabajo, se observó que el incremento de cuadros con huellas sobre las diferentes unidades florísticas fue uniforme. Posiblemente, la escasa cobertura y densidad de la vegetación arbustiva del ANP Loma de Las Tapias no constituye un factor que limite la circulación de vehículos, como sí ocurre en otras áreas protegidas con comunidades vegetales más densas y/o con un estrato arbóreo presente (Brooks \& Lair, 2005). En este sentido, es esperable que el impacto provocado por el tránsito vehicular sea más severo sobre sistemas áridos e hiperáridos (como el existente en Loma de Las Tapias) que sobre ambientes más húmedos, ya que las tasas de recuperación de la vegetación y del suelo dependen en gran medida de la disponibilidad recursos escasos como agua y nutrientes (Brooks \& Lair, 2005; Navas Romero et al., 2019).

Si bien no fue evaluado en el presente trabajo, en algunos sitios se observaron huellas vehiculares que alcanzaron un ancho de 6 metros y profundidades superiores a los 1,5 metros. Probablemente las características de las huellas observadas estén relacionadas a los parámetros considerados por otros autores como la frecuencia de uso, el tipo de vehículo, la velocidad de tránsito (Brooks \& Lair, 2005) y a atributos inherentes al suelo como la granulometría, compactación, la cubierta vegetal y la pendiente (Iverson, 1980; Navas Romero et al., 2019).
Es esperable que existan efectos directos e indirectos en el paisaje natural, donde la pérdida de calidad escénica debe ser evaluada como prioridad de conservación del sitio. En este sentido, el tránsito de vehículos provoca voladura de partículas (Goossens et al., 2012), pérdida de cubierta, pérdida de cubierta vegetal (Navas Romero et al., 2019) y cambios en la pendiente y la red de drenaje, exacerbado por la elevada proporción de suelos de tipo huayquerías altamente erodables (Suvires \& Contreras, 2011), donde además se encuentra el yacimiento fosilífero anteriormente mencionado (Contreras \& Baraldo, 2011). Además, el desarrollo de estas actividades provoca aumentos en el vertido de desperdicios, demarcación de huellas con cintas fluorescentes y la emisión de ruidos que probablemente impacten sobre la fauna local.

De las 17 especies endémicas encontradas en Loma de Las Tapias, se destacan en particular algunas cuya distribución está restringida a la provincia de San Juan ( $P$. sanjuanensis y $G$. cladotrichoides). Estas dos especies fueron observadas en las comunidades 4 y 2 respectivamente, con poblaciones aparentemente saludables, aunque esta aseveración debe ser comprobada. Otras especies endémicas de interés aunque de distribución más amplia son $A$. Spegazzinii, Prosopis argentina y A. ephedroides, (Almirón, 2018). Al respecto, Godoy-Bürki et al. (2014) mencionan que las áreas protegidas de la región cuyana, no aseguran actualmente la conservación de la biodiversidad de especies endémicas, enfatizando así la importancia de incluir a la vegetación nativa como prioridad de conservación del área, además del paisaje y el yacimiento fosilífero que fueron los objetivos iniciales de creación del ANP Loma de Las Tapias.

El monitoreo de actividades e impactos a diferentes escalas y la capacitación del personal, son de vital importancia para determinar posibles tendencias de uso antrópico y su relación con la conservación del sitio. Finalmente, la incorporación de capas temáticas construidas con otras variables (por ejemplo, sitios de importancia fosilífera, distribución de fauna local y de especies exóticas, categorización del paisaje, entre otras), enriquecerá la gestión del área protegida. 


\section{Agradecimientos}

Al personal de la Secretaría de Estado de Ambiente y Desarrollo Sustentable de la provincia de San Juan por su colaboración en las tareas de campo. A Márquez, J. y Contreras, V. por sus aportes al conocimiento y conservación de los ambientes naturales de San Juan. Finalmente, agradezco a los revisores anónimos y al editor por sus sustanciales contribuciones en la mejora del presente trabajo.

\section{Bibliografía}

ALMIRÓN, M. 2018. Vegetación del Monumento Natural y Paisaje Protegido Loma De Las Tapias. Departamentos Ullum y Albardón, San Juan (Argentina). Bol. Soc. Argent. Bot. 53: 385-403. https://doi.org/10.31055/1851.2372.v53.n3.21313

BRATTON, S., M. HICKLER \& J. GRAVES. 1979. Trail erosion patterns in Great Smoky Mountains National Park. Environ. Manage. 3:431-445. https://doi.org/10.1007/BF01866582

BROOKS, M. \& B. LAIR. 2005. Ecological effects of vehicular routes in a desert ecosystem. Report prepared for the United States Geological Survey, Recoverability and Vulnerability of Desert Ecosystems Program (http://geography.wr.usgs.gov/mojave/rvde)

CABRERA, A. 1976. Regiones fitogeográficas argentinas. En: Enciclopedia argentina de agricultura $y$ jardinería. Tomo 2. $2^{\text {da }}$ edición. pp. 1-85. Ed. Kugler, W. Buenos Aires.

COLE, D. \& N. BAYFIELD. 1993. Recreational trampling of vegetation: Standard experimental procedures. Biol. Conserv. 63: 209-215. https://doi.org/10.1016/0006-3207(93)90714-C

CONTRERAS, V. 2010. Zonificación geológicapaleontológica para el diseño del plan de manejo del ANP Loma de Las Tapias (Ley Prov. N ${ }^{\circ}$ 7307), San Juan, Argentina. Informe Proyecto de Extensión: “Área Natural Protegida Loma de Las Tapias (Ullum y Albardón): Una Herramienta para la Educación, el Turismo y el Desarrollo Sustentable". Convocatoria CONEX 2008 - 2010, Res. No 668 Rectorado, Universidad Nacional de San Juan.

CONTRERAS, V. \& J. BARALDO. 2011. Calibration of the Chasicoan-Huayquerian stages boundary (Neogene), San Juan, western Argentina. En: Cenozoic Geology of the Central Andes of Argentina. Pp. 111-121. Ed. SCS Publisher. Salta, Argentina.
DUNIWAY, M., J. HERRICK, K. JASON \& J. VAN ZEE. 2010. Assessing transportation infrastructure impacts on rangelands: Test of a standard rangeland assessment protocol. Rangeland Ecol. Manage. 63:524-536.

https://doi.org/10.2111/REM-D-09-00176.1

GODOY-BÜRKI, A., P. ORTEGA-BAES, J. SAJAMA \& L. AAGESEN. 2014. Conservation priorities in the Southern Central Andes: mismatch between endemism and diversity hotspots in the regional flora. Biodivers. \& Conservation 23: 81-107. https://doi.org/10.1007/s10531-013-0586-1

GOOSSENS, D., B. BUCK \& B. MCLAURIN. 2012. Contributions to atmospheric dust production of natural and anthropogenic emissions in a recreational area designated for off-road vehicular activity (Nellis Dunes, Nevada, USA). J. Arid Environ. 78: 80-99. https://doi.org/10.1016/j.jaridenv.2011.10.015

GOOGLE EARTH PRO. 2019. Freeware imagery database. Versión 7.3. Disponible en: https://www. google.com/earth/

GRENKE, J., J. CAHILL \& E. BORK. 2018. Quantification of multi-use trail effects using a rangeland health monitoring approach and Google Earth. Nat. Areas J. 38: 370-379.

HOSIER, P. \& EATON, T. 1980. The impact of vehicles on dune and grassland vegetation on a south-eastern North Carolina barrier beach. J. Appl. Ecol. 17: 173182. https:// doi.org/10.2307/2402972.

IVERSON, R. 1980. Processes of accelerated pluvial erosion on desert hillslopes modified by vehicular traffic. Earth Surf. Processes. 5: 369-388. https://doi.org/10.3375/043.038.0506

KELLY, J. 2014. Effects of human activities (raking, scraping, off-road vehicles) and natural resource protections on the spatial distribution of beach vegetation and related shoreline features in New Jersey. J. Coast. Conserv. 18: 383-398. https://doi.org/10.1002/esp.3760050407

KÖPPEN, W. 1931. Grundriss der Klimakunde. Ed. De Gruite, Berlin.

KUTIEL, P., EDEN, E. \& ZHEVELEV, Y. 2000. Effect of experimental trampling and off-road motorcycle traffic on soil and vegetation of stabilized coastal dunes. Israel. Environm. Conservation 27: 14-23. https://doi.org/10.1017/S0376892900000035

LEY PROVINCIAL No: 7307. 2002. Disponible en http://diputadossanjuan.gob.ar/leyes-sancionadas/ item/2018-ley-n-7307. 


\section{G. Almirón - Evaluación de huellas vehiculares en áreas protegidas}

NAVAS ROMERO, A., M. HERRERA MORATTA, A. DALMASSO \& A. BARROS. 2019. Quad bike impacts on vegetation and soil physicochemical properties in an arid ecosystem. Acta Oecol. 97: 14-22. https://doi.org/10.1016/j.actao.2019.04.007

PLANTAS ENDÉMICAS DE LA ARGENTINA. Página web disponible en: http://www.lista-planear.org

POBLETE, A. \& J. MINETTI. 1999. Configuración espacial del clima de San Juan. Síntesis del Cuaternario de la Provincia de San Juan. $11^{\circ}$ Reunión de Campo del Cuaternario. INGEO, Universidad Nacional de San Juan, San Juan.

PSARALEXI, M., N. VOTSI, N. SELVA, A. MAZARIS \& J. PANTIS. 2017. Importance of roadless areas for the European Conservation Network. Front. Ecol. Evol. 5: 2. https://doi.org/10.3389/fevo.2017.00002
QGIS, EQUIPO DE DESARROLLO. 2019. Sistema de información geográfica de código abierto. Fundación Fuente Geoespacial. Versión 3.4.2-Madeira. Disponible en: https://qgis.org/ es/site/

RODRÍGUEZ, D. 2004. Estudio sedimentológico y estratigráfico del Neógeno superior de Loma de Las Tapias, con el fin de interpretar la evolución del antiguo rio San Juan (Tesis de licenciatura, Universidad Nacional de San Juan, Argentina).

SUVIRES, G. \& V. CONTRERAS. 2011. Late Cenozoic geology and geomorphology of the Loma de Las Tapias area, San Juan, west central Argentina. En: Cenozoic Geology of the Central Andes of Argentina, pp. 427-436. Ed. SCS Publisher. Salta, Argentina. 
